\title{
The Navstar Global Positioning System: \\ A Global Utility?
}

Irene A. Miller

Southern Illinois University

\begin{abstract}
Satellite-based navigation systems are one of the fastest growing sectors of the space industry. The Navstar Global Positioning System (GPS) is a fully operational US military satellite-based navigation system. New applications, both civilian and military, are continually being developed for GPS and increasing numbers of users worldwide are becoming dependent upon this technology. The airline industry is but one segment of the rapidly growing GPS user base. New technologies evolving from GPS are quickly advancing the usefulness of GPS, which presents the need for international and national policy. The users of GPS technology, such as the airline industry, are having considerable influence over the development of GPS policy as a result of civil users exercising increasing control over the system.

The use of GPS for navigation by the airline industry presents the unique challenge of integrating air and space law. This paper will discuss pertinent legal and policy issues that will affect the development of GPS policy such as liability, sovereignty, and GPS availability. According to some authorities, as GPS becomes an international utility it may present the requirement for an international organization, like the International Civil Aviation Organization (ICAO) or another consortium to establish the policy. The International Telecommunication Satellite Organization (INTELSAT) may serve as a model for a navigational consortium. This paper examines the various national and international organizations that may serve as models to develop GPS policy in the future.
\end{abstract}

\section{Introduction}

Space-based navigation systems, such as the Navstar Global Positioning System (GPS), are one of the fastest growing sectors of the space industry. New applications, both civilian and military, are continually being developed for GPS and increasing numbers of users worldwide are becoming dependent upon this technology. The airline industry is but one segment of the rapidly growing GPS user base. New technologies evolving from GPS are quickly advancing the usefulness of GPS, which presents the need for formulating international and national policy. The use of GPS for navigation by the airline industry presents a unique challenge of integrating air and space law. This paper discusses pertinent issues that will affect the development of GPS policy such as liability, sovereign control of assets, and GPS availability. This paper also examines the various national and international organizations that have developed, or may develop, GPS policy in the future. 


\section{Legal Issues}

\section{Sovereignty}

The use of GPS for navigation by the airline industry presents the unique challenge of integrating air and space law. Air law is derived primarily from The Convention on International Civil Aviation (Chicago Convention). It recognizes that states have exclusive sovereignty over airspace above their territory (Larsen, 1993). Sovereignty means that a nationstate has total jurisdiction and control over all internal actions, people, and resources within its borders. Aircraft must operate within this legal regime based upon national sovereignty.

However, the GPS satellites exist in outer space where a different legal regime applies. The Treaty on Principles Governing the Activities of States in the Exploration and Use of Outer Space including the Moon and Other Celestial Bodies (Outer Space Treaty) states that "outer space, including the moon and other celestial bodies is not subject to national appropriation by claims of sovereignty, use or occupation, or by any other means” (Outer Space Treaty, 1967). Nonappropriation of outer space means that no sovereign state can claim outer space for itself. It also states "A State Party to the Treaty on whose registry an object launched into outer space is carried shall retain jurisdiction and control over such object, and over any personnel thereof, while in outer space or on a celestial body" (Outer Space Treaty, 1967). Outer space itself is not subject to sovereign appropriation but nations exercise sovereignty over space objects like GPS satellites. Space law changed the traditional application of sovereignty, which is the cornerstone of air law. There are fundamental differences between the legal regimes that govern outer space, where GPS is located, and those regimes governing sovereign airspace.

\section{Air and Space Law: Choice of Law}

The use of a space-based navigation system for aircraft navigation presents the choice of which law will apply. In the future, aerospace law may be established and will be common to both types of law. The Future Air Navigation System (FANS) will play a crucial role in the integration of air and space law, resulting in the development of aerospace law (Bhatt, 1994). FANS combines aircraft navigation, the use of which is based upon sovereignty, with spacebased systems that operate in an environment based upon nonsovereignty. FANS will provide immense safety and economic benefits based on international cooperation. However, the benefits provided by the FANS cannot be realized unless the system is implemented globally, which will depend upon international cooperation. At least some observers believe that cooperation is beginning to replace the notion of sovereignty with the world's airline industry moving toward deregulation and pursuit of a global market economy (Bhatt, 1994).

Currently, nation-states are responsible for developing, implementing, and maintaining their ground-based air navigation systems. Nation-states must adhere to international Standards and Recommended Practices (SARPs), established by the International Civil Aviation Organization (ICAO), but they also are responsible for developing their own domestic regulations, procedures, and policy regarding air navigation. Nation-states would forfeit some control over their air navigation systems if they use GPS; therefore, their claim of absolute sovereignty over airspace may be weakened over time. Nation-states are concerned about the ramifications of civil aviation using GPS as their primary means of air navigation. They are 
concerned that this arrangement will cause them to become dependent upon the US for air navigation services. This entails becoming dependent upon the US military, which operates GPS. The fact that GPS is controlled by the US military is a major obstacle to its international acceptance (Kaiser, 1994). Furthermore, the shutdown of ground-based domestic navigation aids would give the US tremendous bargaining power over nations at the end of the ten or fifteen year operating period (Kaiser, 1994). Nation-states do not want to become dependent upon the US for their air navigation system because it places them in a vulnerable position.

The international community may only receive the immense benefits from a space-based navigation system with the acceptance of certain limitations on national sovereignty. As nationstates began engaging in space activities it affected their sovereign rights, and their relationships with and within the international community. As a result of space activities, nation-states are less able to control the information that enters and leaves their borders (Wriston, 1988). For instance, individuals anywhere in the world, with a GPS receiver, can access the navigation information provided by GPS regardless of their location. A sovereign nation may not be able to prevent an individual, within their borders, from using the navigation information provided by GPS. In a strict sense, they cannot control the GPS signal that is penetrating their sovereign airspace. Nation-states can prevent airlines under their regulatory control from using GPS. However, as the immense benefits provided by GPS grow, it will become increasingly difficult to prevent its use. Political pressure may eventually cause nation-states to authorize the use of GPS for the aviation community.

\section{Liability Implications}

There is growing concern regarding the potential liability implications of GPS as a result of the increase in civil users and applications. In the past, the US government stated that the use of GPS data was strictly at the user's own risk until the system became fully operational (Spradling, 1990). Now that the system is fully operational the issue of liability must be addressed. Liability is an important legal issue affecting the operation of GPS partly because the risk of personal injury and damages is an economic factor (Larsen, 1993).

There are two pertinent sources of potential liability regarding GPS. The ability to warn users of erroneous information or degraded coverage is one source of liability (Spradling, 1990). The US government is under no legal obligation to provide GPS data to civil users, but they must exercise due care in ensuring the system is functioning properly and must warn users promptly when it is not (Spradling, 1990). In short, when the government offers navigation services, thereby inducing users to rely upon that service, they may be liable for damages caused by their negligence.

Currently, GPS provides two warning mechanisms. First, a satellite health message is transmitted as part of the GPS signal that is received by users (Spradling, 1990). The second warning mechanism, specific to aviation users, is the Notice to Airmen (NOTAM) system. Selective Availability (SA) is the second potential source of liability only if the Standard Positioning Service (SPS) accuracy is not maintained as published (Spradling, 1990).

The scope of liability must be discussed to ascertain the circumstances under which the US government might be held liable for injury and damages resulting from the operation of GPS. The US may assert sovereign immunity as a defense to any claim, which means the government 
must consent to be sued (Spradling, 1990). However, the U.S. Congress has passed several laws that waive immunity in certain instances. The Federal Tort Claims Act (FTCA) waives governmental immunity in claims against the US for damages arising from a loss of property, personal injury, or death, "caused by the negligent or wrongful act or omission of any employee of the Government while acting in the scope of his office or employment under circumstances where the United States, if a private person, would be liable to the claimant in accordance with the law of the place where the act or omission occurred” (US Code, 1346 (b)).

The waiver of governmental immunity is qualified by several important statutory exceptions which reinstate the government's immunity status. Three of the statutory exceptions are particularly important in regards to GPS. Two exceptions include discretionary acts and claims arising in foreign countries. Generally, the government cannot be sued in these instances. However, if the claim is based on facts where the government's conduct was negligent, it may still be possible to bring a claim.

The discretionary function exception is the most important of the three. This exception states that sovereign immunity will not apply to claims arising out of "the exercise or performance or the failure to exercise or perform a discretionary function or duty on the part of a federal agency or an employee of the government” (US Code 2680, (a)). For example, in 1980 a federal court stated that the government's decision to illustrate a television tower on an aeronautical chart, into which the plaintiff's spouse crashed their aircraft, was a discretionary act. Once the government decides to depict these hazards on the charts, then they can be held liable if it is not done correctly (Spradling, 1990). In this case, the court ruled that the government was not liable because the television tower was depicted properly on the chart. The government's decision to degrade the accuracy of the Precision Positioning Service (PPS) to that available through the SPS, by implementing SA, is discretionary. The government can be held liable in cases involving the SPS, since it is a discretionary act, but they cannot be held liable for PPS because it is not discretionary. For instance, Acme Airline cannot sue the government for damages resulting from an accident claiming that the accident would not have occurred if they had access to the PPS, instead of the SPS.

The second exception to the FTCA's waiver of governmental immunity is that it is inapplicable to situations where the claim arises in a foreign country (US Code, $2680(\mathrm{k})$ ). When the facts indicate that the negligent act took place in international airspace or outer space, the fact that the outcome occurs in a foreign country or territory does not rule out the possibility of claims under the FTCA (Spradling, 1990). For example, if an Acme Airlines aircraft crashes in Italy, caused by a negligent act which caused erroneous GPS data to be uplinked to a satellite from the Master Control Station in Colorado, then the airline can make a claim against the US government under the FTCA. The third and last exception, claims arising out of combat activities, is more narrow requiring only that combatant activities be the cause of the damages. If combatant activities "caused" the government to degrade or delete the SPS signal then the government would be immune without the question of negligence being raised (US Code, 2680 (j)).

In summary, there are some important general principles that are probably relevant to the liability implications of GPS for the US government. First, the US most likely has a duty to warn civil users of problems within the system that may cause an adverse result. The inability to warn users of system failures in real time is of great concern, particularly to the aviation community. The legal implications of this deficiency are uncertain at this time. The US will be held liable for operational level negligent acts or omissions. The US most likely will not be 
liable for damages as a result of the combat activities of the US military. Lastly, it probably will be the responsibility of the civil GPS users to match the known capabilities and limitations of GPS with the degree of risk involved with their activities (Spradling, 1990).

The unique features of GPS distinguish it from similar air traffic control and groundbased air navigation system cases. The geographical coverage is greater than any previous air navigation system, extending beyond US territory and international waters. Another cause for concern is that, in theory, there is a potential for a major catastrophe. Should the system experience a massive failure, thousands of users would be impacted at once (Spradling, 1990). For example, a complete system failure would have disastrous consequences for a Boeing 747400. It can carry over 400 passengers, flying over long Pacific routes using GPS as the primary means of navigation, without Omega or inertial navigation system backup. To date, the issue of liability implications regarding GPS has received little attention from the legal community. Eventually this issue will be brought to the forefront as the world's airline industry, along with other civil users, increasingly utilize and become dependent upon GPS technology.

\section{Institutional Considerations}

Currently, there are no institutions that have the broad mandate needed to establish policies regarding the aviation community's use of space-based navigation systems for air navigation. However, there are several organizations that may be qualified to regulate certain aspects of GPS applications.

\section{International Civil Aviation Organization (ICAO)}

The Chicago Convention governs navigation of aircraft. It establishes the objectives of ICAO, which are the orderly growth of civil aviation worldwide, development of aircraft designs, and development of airways and airports (Chicago Convention, 1944). Most importantly, ICAO is charged with ensuring that the world is provided with safe, regular, efficient, and economical air transportation (Bhatt, 1994). ICAO is the institution that develops minimum SARPs for use of navigation satellites by aircraft. Based on the Chicago Convention, member-states are responsible for implementing the initiatives adopted by ICAO in the form of SARPs (Larsen, 1994).

ICAO, through the implementation of the FANS, is ensuring that its objectives will be fulfilled well into the twenty-first century. The implementation of a revolutionary technology such as FANS will require global coordination based on accepted policies. Member-states have recognized the need for ICAO's leadership in the global implementation of FANS, which is necessary for all nations to realize the benefits of this space-based technology (Kotaite, 1994). To respond to its member-states' request, the ICAO Council established a high-level task force, consisting of twenty-two capable individuals with managerial experience at the senior executive level in the international airline industry. The role of the task force is to advise the Council on the most effective method of implementing the FANS (Kotaite, 1994). The establishment of the Task Force and development of new policy has demonstrated ICAO's success toward integrating a space-based navigation system, such as GPS, into the aviation community.

However, the implementation of FANS, which is a space-based technology, will increase 
ICAO's involvement in establishing space law and policy. The question at hand is whether ICAO is the proper institution to establish policies regarding the aviation community's use of space-based navigation systems for air navigation. ICAO already serves as a forum for the discussion of issues relating to the use of navigation satellites for air navigation, communication, surveillance, and air traffic management. ICAO also examines legal issues pertaining to the providers and users of navigation satellites (Larsen, 1994). To date, ICAO has been able to accommodate the wide variety of changes that have occurred in the world's aviation community.

Some of these monumental changes were the introduction of the jet age and wide-body aircraft, which had not only a tremendous impact on the aviation community but the entire world. The use of space-based navigation systems for communication, air traffic management, and air navigation is having a similar impact.

ICAO has been successful in regulating and establishing policy for the world's civil aviation community for over 50 years. It is likely that ICAO is the proper institution to regulate and establish policy for the aviation community's use of space-based navigation systems. Although the involvement of space technology is a new element added to the traditional concept of airspace, it does not change the fact that ICAO is the only global institution that has the jurisdiction to regulate specific issues of aeronautical communications, air navigation aids, and other issues concerned with the safety, regularity, and efficiency of air navigation.

\section{Office for Outer Space Affairs}

The United Nations (UN) Office for Outer Space Affairs would perhaps be a more appropriate organization to implement and establish policy for the use of GPS and other spacebased navigation systems. The Office for Outer Space Affairs is tasked with promoting the use of space technology applications, and implementing the decisions of the General Assembly and United Nations Committee for the Peaceful Uses of Outer Space (UNCOPUOS) relating to the peaceful uses of outer space (United Nations, 1992). However, the Office for Outer Space Affairs does have a broad mandate that accommodates all the civil uses of space-based navigation systems and their function is somewhat regulatory in nature. ICAO has the more specific function of regulating the international aviation community, and is becoming increasingly involved with regulating the aviation community's use of GPS. However, GPS is a space-based system, which implies that the Office for Outer Space Affairs would be responsible for regulating its use. Perhaps in the future, it may be beneficial for both ICAO and the Office for Outer Space Affairs to work together in regulating and establishing policy for the international aviation community's use of space-based navigation systems. Presently, there are no organizations that have extensive experience developing both the aviation and space policy that would be required for aviation-related GPS applications. Therefore, some observers have suggested that perhaps an international consortium would be the appropriate institution to develop and implement policy regarding aviation and other GPS applications.

\section{International Telecommunications Satellite Organization (INTELSAT)}

The consortium frequently cited as a model for a GPS consortium is INTELSAT. INTELSAT is a telecommunications satellite consortium begun in 1965 with one satellite, and 
has expanded to a network of nineteen satellites connecting over 750 Earth station antennas (Potter, 1992). The INTELSAT Agreement and Operating Agreement established INTELSAT as a "single global commercial communications satellite system" to "provide expanded telecommunications services to all areas of the world" (White and White, 1988). INTELSAT consists of 136 countries, all of which are part owners (de Selding, March 1996). INTELSAT shares are a capital contribution that is proportional to an ownership share in the satellite cooperative. However, the amount of capital investment is adjusted annually to represent the percentage of utilization made of the system by each member. Utilization charges from various services are in addition to ownership costs and this constitutes INTELSAT's operating revenues (White and White, 1988). INTELSAT's role is the space segment provider and system design authority. In terms of business, it does not sell services to the end users; instead it recovers the cost of their activities from the ground segment operators who provide the services to end users (Shin, 1993).

INTELSAT has many positive attributes that support its use as a model for an international navigation satellite consortium. Ownership in such an organization is held internationally and membership is voluntary. Another practical attribute of INTELSAT is that it allows for the formation of a large critical mass where economies of scale can be achieved (Potter, 1992).

Space-based navigation technology would be able to achieve economies of scale, as did telecommunication technology, through the creation of an international consortium and developing cheaper technology. It would be advantageous for an international navigation satellite consortium to duplicate the positive characteristics of INTELSAT.

There are also many attributes of INTELSAT that are incompatible with an international navigation satellite consortium. INTELSAT was created to provide global coverage, which GPS already provides (Potter, 1992). It was also established to provide critical infrastructure, but the space and control segment infrastructure for GPS is already in place (Potter, 1992). However, more infrastructure will be needed if GPS is to be used by the aviation community. For example, countries will have to develop and implement augmentation systems, similar to the Federal Aviation Administration's (FAA) Local Area Augmentation System (LAAS), that will allow aircraft to use GPS for instrument approaches. The enormous costs associated with building a global satellite network, considering the short design life and large size of early satellites, required vast financial resources (Potter, 1992). The size, design life, and overall costs associated with building satellites have decreased dramatically since INTELSAT was formed. The GPS satellites are highly sophisticated and have a design life of over seven years.

The structure of an international navigation satellite consortium would need to be consistent with the growing commercialization of space activities and should encourage competition. Any future international navigation satellite consortium should incorporate some of INTELSAT's characteristics, such as non-discriminatory access and voluntary participation, but should not use the organization as a strict model. The political environment and circumstances under which INTELSAT was created are considerably different from those of today. 


\section{Policy Issues}

\section{Accessibility and Control}

GPS was originally conceived as a military space-based navigation system during the Cold War. GPS was part of the space race with the former Soviet Union in which both sides were trying to dominate the new "high ground." A study conducted by the National Academy of Public Administration (NAPA) and the National Research Council (NRC) stated that GPS "is rapidly becoming a de facto global utility with immense benefits" (NAPA \& NRC, 1995). The idea that GPS is becoming a "de facto global utility" is inconsistent with the US exercising absolute control over GPS. GPS has been extremely successful in regards to accomplishing its military objectives. However, it has also produced invaluable benefits to many civil users worldwide. As a result of civil utilization of GPS, future policy must also focus on international cooperation and nondiscriminatory access, as well as its strategic value. The Outer Space Treaty states that, "The exploration and use of outer space, including the moon and other celestial bodies, shall be carried out for the benefit and in the interest of all countries" (Outer Space Treaty, 1967). The principle of freedom of outer space is based on the idea that the interests of the entire world community are best served through freedom and not on absolute control by a few nations. International law requires states that have accepted the Treaty to carry out the exploration and use of outer space in the common interest of all humankind.

Control was identified as a crucial element in determining international acceptance of GPS as an air navigation system. Currently, GPS is controlled by the US military. User-states are concerned that GPS service can be interrupted or the precision can be downgraded at the discretion of the US military. The use of GPS for air navigation will require substantial investments by the user-states; therefore, they will need a commitment from the US that they will provide nondiscriminatory access to the corresponding user-states (Shin, 1993). For instance, it would cost user-states millions of dollars to develop a system, similar to the FAA's Wide Area Augmentation System (WAAS), that enables aircraft to utilize GPS as the primary source for enroute air navigation. However, over time it will be less expensive to develop and operate a GPS-based air navigation system, as compared to the current ground-based systems.

There are several options that would address concerns regarding nondiscriminatory access and establish equitable control for user-states. Contractual relationships in some form may provide adequate control for user-states (Kaiser, 1994). Multilateral and bilateral agreements, similar to those already used in the airline industry, between the US and user-states may also be an acceptable alternative. Another option is the establishment of an international navigation satellite consortium similar to the INTELSAT. INTELSAT functions on the basis of nondiscriminatory access and equitable control for member-states (Shin, 1993). A formal contractual relationship would be a legal method to bind the US to comply with user requirements.

There are many reasons why it is in the best interest of the US to encourage the international acceptance of GPS by meeting the concerns about control. First, it would give the US an opportunity to institute user charges (Kaiser, 1994). The user-state must be willing to contribute financially to the operation of GPS when they are granted guaranteed access through some form of control. A contractual agreement between the US and a user-state would require that the user pay a predetermined amount for the navigation services used. Under this type of agreement the US would be more willing to make GPS available for a longer period than the ten 
or fifteen year operating period (Kaiser, 1994). Furthermore, if the US does not take further steps to promote the acceptance of GPS, other nations will be inclined to use the Global Navigation Satellite System (Glonass) or develop their own space-based navigation system.

The US, being a leader in space exploration and a signatory to the Outer Space Treaty, has the responsibility of facilitating international cooperation and making the benefits derived from space activities available to all nations. There are several courses of action that can be taken by the US to promote the international acceptance of GPS. The US should reassert its commitment to provide permanent international access to GPS and state its intention to consider international interests in the future development of the system (NAPA \& NRC, 1995). SA should be eliminated because its military effectiveness is undermined by the existence of augmentation systems such as Differential GPS (D-GPS) (NAPA \& NRC, 1995). The continuing degradation of the GPS signal through SA is a great inconvenience for civil users. Furthermore, the military's use of SA promotes uncertainty among civil users worldwide about the US's commitment to provide access to GPS (NAPA \& NRC, 1995). The military will maintain its position regarding SA until they develop an alternative method to retain the strategic value of GPS.

According to at least one view, the political feasibility of further degrading the SPS signal for military purposes is quickly diminishing (NAPA \& NRC, 1995). For example, further degradation of the signal, once the world's airline industry becomes dependent upon GPS as their primary source of navigation, would have disastrous consequences. The Department of Defense (DOD) discussed GPS control and management issues with the Department of Transportation (DOT). If the DOD relinquished some GPS control to the DOT it would ease concerns of the international community regarding the military's operation of the system (NAPA \& NRC, 1995). Also, the DOT would be a competent U.S. government representative for negotiating any contractual agreements with user-states.

\section{The Federal Radionavigation Plan: Toward an Integrated Federal Policy}

The Federal Radionavigation Plan (FRP) serves as the planning and policy document for all present and future federally provided common-use radionavigation systems (United States FRP, 1995). A memorandum of agreement between the DOD and DOT, signed in January 1993, established the policies and procedures to ensure an effective working relationship between the two departments regarding the civil use of GPS (United States FRP, 1995). There are several objectives of the FRP that are particularly pertinent to the development of GPS policy. The first objective is to establish an integrated federal policy and plan for all common-use civil and military radionavigation systems (United States FRP, 1995). A well-integrated and consistent federal policy will promote international acceptance of GPS and will facilitate its commercial use. The next objective is to define and clarify new or unresolved common-use radionavigation system issues (United States FRP, 1995). GPS was developed as a military system but is becoming a "de facto global utility," which presents many concerns about protecting its role in national security. These and many other issues will have to be resolved through the development of federal policy. The final objective is to provide a focal point for user input (United States FRP, 1995). The amount of user input that will need to be taken into consideration, during the future development of the system and associated policy, will increase as the worldwide user base 
continues to grow.

The FRP contains several US government policies and practices that set a precedent for future GPS policy. First, is the promotion of national and international standardization of civil and military radionavigation aids (United States FRP, 1995). ICAO's FANS facilitates international standardization of civil air navigation systems, which renders increased safety and efficiency for the aviation community. Implementation of GPS as the world's standard in the air is contingent upon international acceptance of the system (United States FRP, 1995). Next, the US government has provided comprehensive management of all federally provided common-use radionavigation systems through DOD/DOT interagency agreements (United States FRP, 1995). This entails some policy making and management functions of GPS being turned over to the DOT from the DOD. The DOD releasing some control of GPS to the DOT may facilitate the international acceptance of GPS.

Lastly, the US government is trying to ensure that the private sector is considered in the development, operation, and maintenance of all the systems required to provide common-use radionavigation aids in support of the FRP (United States FRP, 1995). As the airlines continue to implement GPS into their operations and eventually become dependent upon the system, they will want their concerns and requirements to be considered in the development of policy and in the evolution of the system itself. Together, these policies and practices are establishing a precedent for future GPS policy that will promote international cooperation and commercial growth.

\section{The Federal Aviation Administration's GPS Implementation Plan}

The FAA has developed the GPS Implementation Plan for Air Navigation and Landing, which describes FAA activities in implementing the use of GPS by aviation users for navigation and landing. The FAA is using its Satellite Navigation Program to develop new capabilities that are rendering significant economic and safety benefits to the entire aviation community (FAA, 1994).

The FAA's mission, as stated in the 1994 FAA Strategic Plan, is to provide a safe, efficient and responsive aviation system (FAA, 1994). The US National Airspace System (NAS) is the best in the world; however, its capability is limited by the technology contained in the current systems. The FAA's goals for the future NAS are based upon the implementation of GPS, which will reduce the current technological limitations placed upon the system and increase efficiency (FAA, 1994). To date, the FAA has dealt with many technical aspects of GPS such as establishing standards for the manufacture of GPS avionics. However, they have not been as successful in addressing the coinciding policy issues. The FAA's overall strategy is to work concurrently on the technical, operational, and policy aspects of its Satellite Navigation Program to bring the benefits offered by GPS to the aviation community as soon as possible (FAA, 1994).

\section{GPS Policy Studies: The National Research Council (NRC)/National Academy of Public Administration (NAPA) and RAND/Critical Technologies Institute (CTI)}




\section{NAPA and NRC Study}

The 1994 National Defense Authorization Act mandated that an independent study, funded by the DOD, on the future management and funding of GPS be conducted (NAPA \& NRC, 1995). A report, The Global Positioning System: Charting the Future was published as a result of the joint study conducted by NAPA and the NRC. It builds on the work of previous studies and is intended to advise Congress, the secretaries of defense and transportation, the President, and the American public, on the actions needed to ensure the continued success of GPS in meeting military and civilian needs (NAPA \& NRC, 1995).

The NAPA panel concluded that GPS is an invaluable asset that is quickly becoming a "de facto global utility" (NAPA \& NRC, 1995). The NAPA panel presents some recommendations to help maintain US leadership in satellite radionavigation. First, the President should adopt specific national goals to guide GPS policy and implementation. The US should also maintain its commitment to make GPS available to all users free of direct charges (NAPA \& NRC, 1995). In 1991, the DOT announced that it had no intention of limiting civil access to GPS in the near future, and that it would give at least six years advance notice before implementing any restrictions. Furthermore, the US commitment to keep GPS available for use by the international aviation community was reiterated in a letter from FAA Administrator David Hinson to ICAO in October 1994 (NAPA \& NRC, 1995).

Charting the Future recognizes the importance of GPS to national security. The NAPA panel recommends that the DOD develop the capability to counter adverse use of GPS to retain its military advantage. SA is no longer effective at accomplishing its purpose; therefore, it should be turned down to zero immediately and deactivated after three years (NAPA \& NRC, 1995). Augmentation systems used by the aviation community, such as D-GPS and WAAS, have defeated the purpose of SA, making it an inconvenience for users.

The report recommends further that the US should develop a more effective mechanism of governance by incorporating civil agency participation in policymaking, and offering a greater influence over civilian, commercial, and international interests in the future evolution of GPS (NAPA \& NRC, 1995). The airline industry, being a major user of GPS, should have a stronger voice in the development of the system. Finally, stable federal funding for GPS will be necessary in the interest of national security and public safety. However, the possibility of contributions from other nations due to growing international participation should be pursued as well (NAPA \& NRC, 1995).

The NAPA panel proposes some national goals that will promote the establishment of a national strategy and guidelines for GPS. Several of these goals are of particular importance to the international airline industry. The first goal states that the US should maintain an efficient and effective space-based navigation system that is responsive, highly accurate, and reliable (NAPA \& NRC, 1995). The US should maintain its leadership in space-based navigation systems by promoting the future development of GPS and growth in commercial applications. The US needs to establish policies governing the availability, use, and funding of GPS that are concise and agreeable for all major users. Finally, the US needs to provide a flexible management structure that is capable of adapting to a rapidly changing environment (NAPA \& NRC, 1995).

The NAPA panel further advises, in order to meet these national goals, that the President should promulgate an executive order to develop a national strategy for GPS and establish a GPS Executive Board (NAPA \& NRC, 1995). The Executive Board should be responsible for 
governance oversight, policy setting and guidance, funding, and overall GPS coordination, including augmentation systems. The panel also recommends that the Board's membership extend beyond the DOD and DOT to include a representative group of domestic and international GPS users (NAPA \& NRC, 1995). These recommendations suggest that the world's airline industry will more than likely have a member of the Board that represents their interests.

Overall funding recommendations from the NAPA panel state that Congress and the Administration should treat GPS as a public good, paid for by general tax revenues (NAPA \& NRC, 1995). For national security reasons, it is imperative that funding for GPS come from a consistent and dependable source. It is also proposed that the costs of D-GPS and WAAS could be covered by the Aviation and Airways Trust Fund without raising taxes (NAPA \& NRC, 1995).

GPS funding is an important issue because it presents the question of why US taxpayers should carry the financial burden of supporting a system that benefits users worldwide. In February 1994, the Congressional Research Service (CRS) studied several possible funding mechanisms (NAPA \& NRC, 1995). Initially, CRS considered a user fee for the SPS, but concluded there was no fee collection method that could generate revenue without being cost prohibitive. A profit tax on commercial users was also examined. But it was concluded that this would jeopardize the competitiveness of US companies because collecting the tax from international users would be difficult (NAPA \& NRC, 1995). The willingness of foreign governments and users to support GPS financially is mostly contingent upon the willingness of the US government to permit foreign control and participation in the system's management.

Finally, fees similar to those used for the FAA's Airport and Airways Trust Fund could be used to assess fees for D-GPS services (NAPA \& NRC, 1995). Raising the taxes for the Airport and Airway Trust Fund may be necessary because it will help pay for the cost of augmentation systems and as a possible method of cost recovery for basic GPS activities (NAPA \& NRC, 1995). There are several strong arguments for considering the use of the Trust Fund as a revenue source for GPS. The fund already exists so no additional legislation would be necessary to create tax-collecting mechanisms, and those affected would already understand the mechanism. The revenue that could be generated through the Trust Fund would be significant. The latest estimates for the Airport and Airways Trust Fund indicate that the balance in the trust fund will grow to $\$ 9.3$ billion by the year 2000 (NAPA \& NRC, 1995). The US airline industry would more than likely oppose any increase in taxes for the trust fund.

There are also some valid reasons why taxes for the Aviation and Airways Trust Fund should not be raised, but the funds can still be used to meet GPS costs. There seems to be no economic justification, regarding augmentation systems, for raising the fees. The D-GPS and WAAS have been justified by the FAA and the US Coast Guard on the basis of cost-benefit studies (NAPA \& NRC, 1995). It is important to proceed cautiously with regards to increasing trust fund taxes because the system may change in the near future to allow a more direct-charge system based on the proposal to corporatize the FAA (NAPA \& NRC, 1995). Most importantly, the airline industry is trying to emerge from financial difficulties and increasing Trust Fund taxes could result in an added financial burden on the industry. The US airline industry lost \$10 billion dollars from 1991 through 1993, but many airlines have reported profits since 1995. 


\section{RAND's CTI Study}

The White House Office of Science and Technology Policy (OSTP) and the National Science and Technology Council (NSTC) asked RAND's Critical Technologies Institute (CTI) to examine the major policy issues regarding GPS and to recommend solutions for addressing them (CTI, 1996). The report, titled The Global Positioning System: Assessing National Policies, was conducted by CTI and released in March 1996. CTI's report identifies the US government's lack of clear GPS policy as a key issue. CTI suggests that the US develop broad GPS policy that will serve as a guideline for more comprehensive policy in the future. It is important that this policy consider the interests of military, commercial, and international GPS users. Also, the policy should reassure all users that GPS will continue to operate in a stable, reliable manner, and provide civilian signals free of direct charges (CTI, 1996).

CTI makes several strong recommendations concerning the strategic value of GPS. CTI's study states that the US should ensure the GPS space segment remains subject to its control in order to protect national security interests (CTI, 1996). The study states that the US should ensure that GPS is funded and maintained in a stable manner, free of direct user charges, to promote the international acceptance of GPS (CTI, 1996). CTI's study also suggests that local-area augmentations should not be managed by international organizations because of their limited range, national interest in retaining local control, and a lack of effective methods of enforcing international control (CTI, 1996). Most local-area augmentations are already under the control of the private sector and national governments. Furthermore, the study provides that international governance of wide-area augmentations would enhance the international acceptance of GPS (CTI, 1996). Finally, the US should not deter the development of private ground augmentation services except when national security and public safety are compromised (CTI, 1996).

In regards to foreign policy, the study recommends that the US try to facilitate international participation in providing commercial GPS-related goods and services. However, the US should refrain, and encourage other nations to refrain, from providing wide-area augmentations until mechanisms, like military countermeasures or diplomatic agreements, are put in place that would deal with misuse (CTI, 1996).

\section{Comparing and Contrasting the Two Studies}

The two studies are different in several aspects. Some of the disparity between the studies may stem partly from the sponsoring organizations' dissimilar backgrounds. NAPA and the NRC are affiliated with the civilian sector and tend to represent the interests of the scientific community. Conversely, although RAND is no longer directly affiliated with the military, they often tend to reflect military interests due to their strong affiliation in previous years. The NAPA and NRC study recognizes the importance of GPS to national security, but they recommend the eventual deactivation of SA. The study recommends that the DOD develop new technology that allows them to retain the strategic value of GPS. The CTI study favors the DOD's position much more strongly. For instance, the CTI study recommends that the DOD retain control over GPS. The NAPA and NRC study suggests that some control over GPS might be transferred to the DOT. Next, the CTI study states that the US government should continue funding GPS, because a stable and reliable funding source is essential. Conversely, the NAPA 
and NRC study presents the possibility of developing alternative funding sources.

The two studies are similar in several aspects as well. First, both studies recognize GPS as a valuable asset and that the number of users is rapidly increasing worldwide. They conclude that the US should maintain its commitment to make GPS available to all users free of direct charges. The availability of GPS directly affects the international acceptance of GPS, which both studies also identify as an important issue. The studies state further that it is important for the US to maintain its leadership in satellite radionavigation. They both recommend that the US develop GPS policy that considers the needs of civil, commercial, and international users. Although both studies recognize the importance of the civil uses of GPS, the CTI study strongly recommends that the civil applications of GPS not take precedence over military applications or degrade the strategic value of GPS.

\section{The Clinton Administration's GPS Policy}

The development of uniform GPS policy is identified as a key issue in both studies. On March 29, 1996, the Clinton Administration announced its new GPS policy. The White House OSTP, and the White House National Security Council were responsible for developing the new government policy on GPS (de Selding, April 1996). The policy promises that commercial users will continue to have access to the GPS signal without charge. The policy also states the US government will turn SA to zero within ten years (de Selding, April 1996). This will give the military adequate time to develop a new method of denying enemies access to the GPS signal. The Clinton Administration contends that the new GPS policy will promote the already rapid commercialization of GPS services.

\section{Conclusion}

Comprehensive GPS policy needs to be established and should address pertinent issues such as liability, sovereignty, and availability. The DOT, FAA, and ICAO are national and international organizations that will develop future GPS policy. However, the creation of an international navigation satellite consortium is a viable alternative as well. It is evident that any policy must be based upon the values established in the Outer Space Treaty. International cooperation must be the

cornerstone of future GPS policy, especially with the development of many foreign GPS augmentation systems. GPS is an extraordinary navigation system providing benefits that have only begun to be realized.

\section{References}

Bhatt, S. (1994). Future Air Navigation Systems and ICAO: A New Look For Global Aviation Interacting with Space Law Regime. Proceedings of the Thirty-Seventh Colloquium on the Law of Outer Space, 3-5.

The Convention on International Civil Aviation, 1944.

Critical Technologies Institute. (1995). The Global Positioning System: Assessing National 
Policies. Santa Monica: Rand.

de Selding, Peter B. (1996, March 25-31). Intelsat Drops Long March; Board Cancels Three Contracts. Space News, p. 1 \& 26.

de Selding, Peter B. (1996, April 1-7). GPS Policy Influences Inmarsat. Space News, p. 1\& 21.

Federal Aviation Administration (FAA). GPS Implementation Plan for Air Navigation and Landing. Washington: FAA, 1994.

Gorove, Stephen. (1977). Sovereign Rights In Outer Space. Proceedings of the Twelfth Colloquium on the Law of Outer Space, 244-250.

Kaiser, Stefan A. (1994). Aeronautical Satellite Navigation: Civil Aviation’s Needs and Institutional Alternatives. Proceedings of the Thirty-Seventh Colloquium on the Law of Outer Space, 25-31.

Kotaite, Assad. (1994). ICAO Ushers in a Revolution in Global Navigation Technology. Annals of Air and Space Law, XIX-I, 337-344.

Larsen, Paul B. (1993). Legal Liability for Global Navigation Satellite Systems. Proceedings of the Thirty-Sixth Colloquium on the Law of Outer Space, 69-75.

Larsen, Paul B. (1994). Positioning Satellites: Current Institutional Issues. Proceedings of the Thirty-Seventh Colloquium on the Law of Outer Space, 32-39.

National Academy of Public Administration (NAPA) \& National Research Council (NRC). The Global Positioning System: Charting the Future. Washington: NAPA, 1995.

Potter, Michael. (1992). International Satellite Organizations: From Monopoly to Cartel. Proceedings of the Thirty-Fifth Colloquium on the Law of Outer Space, 120-127.

Shin, Hong-Kyun. (1993). Legal Aspects of Space Activities of ICAO in Implementing FANS. Proceedings of the Thirty-Sixth Colloquium on the Law of Outer Space, 98-115.

Spradling, Kevin K. (1990). The International Liability Ramifications of the U.S. Navstar Global Positioning System. Proceedings of the Thirty-Third Colloquium on the Law of Outer Space, 93-101.

The Treaty on Principles Governing the Activities of States in the Exploration and Use of Outer Space, including the Moon and Other Celestial Bodies, 1967.

United Nations. Space Activities of the United Nations and International Organizations. New York: United Nations, 1992.

United States. Department of Defense \& Department of Transportation. 1994 Federal Radio Navigation Plan. Washington: National Technical Information Service, 1995.

United States Code 1346 (b).

United States Code $2680(\mathrm{a}),(\mathrm{j})$, \& ( $\mathrm{k})$.

White, R. \& White, H. (1988). The Law and Regulation of International Space Communication. Boston: Artech House.

Writson, Walter B. (1988). Technology and Sovereignty. Foreign Affairs, 67 (2), 63-75. 


\section{List of Acronyms}

$\begin{array}{ll}\text { CRS } & \text { Congressional Research Service } \\ \text { CTI } & \text { Critical Technologies Institute } \\ \text { D-GPS } & \text { Differential GPS } \\ \text { DOD } & \text { Department of Defense } \\ \text { DOT } & \text { Department of Transportation } \\ \text { FAA } & \text { Federal Aviation Administration } \\ \text { FANS } & \text { Future Air Navigation System } \\ \text { FRP } & \text { Federal Radionavigation Plan } \\ \text { FTCA } & \text { Federal Tort Claims Act } \\ \text { GLONASS } & \text { Global Navigation Satellite System } \\ \text { GPS } & \text { Global Positioning System } \\ \text { ICAO } & \text { International Civil Aviation Organization } \\ \text { INTELSAT } & \text { International Telecommunications Satellite Organization } \\ \text { LAAS } & \text { Local Area Augmentation System } \\ \text { NAPA } & \text { National Academy of Public Administration } \\ \text { NAS } & \text { National Airspace System } \\ \text { NOTAM } & \text { Notice to Airmen } \\ \text { NRC } & \text { National Research Council } \\ \text { OSTP } & \text { Office of Science and Technology Policy } \\ \text { PPS } & \text { Precision Positioning Service } \\ \text { SA } & \text { Selective Availability } \\ \text { SARPs } & \text { Standards and Recommended Practices } \\ \text { SPS } & \text { Standard Positioning Service } \\ \text { UN } & \text { United Nations } \\ \text { UNCOPUOS } & \text { United Nations Committee for the Peaceful Uses of Outer Space } \\ \text { WAAS } & \text { Wide Area Augmentation System } \\ \end{array}$

